\title{
MANEIRAS DE PESQUISAR NO COTIDIANO: CONTRIBUIÇÃO DA TEORIA DO ATOR-REDE
}

\author{
Ronald João Jacques Arendt \\ Universidade do Estado do Rio de Janeiro, Rio de Janeiro, Brasil
}

\begin{abstract}
RESUMO: A partir da temática geral do XI Simpósio da ANPEPP “Maneiras de pesquisar no cotidiano: contribuições para a formação em pesquisa em Psicologia", e tendo em vista a participação do autor no GT "Cotidiano e Práticas Sociais" da ANPEPP, este texto busca descrever a prática de formação em pesquisa a partir da teoria do ator-rede. Após efetuar a recensão de um texto de Bruno Latour, um diálogo entre um professor e um aluno em que são expostas as principais características da prática de pesquisa no âmbito desta abordagem, o autor busca precisar o posicionamento epistemológico-metodológico da referida teoria assim como suas raízes fundadas na filosofia pragmática, descrevendo sucintamente algumas proposições de William James e John Dewey.
\end{abstract}

PALAVRAS-CHAVE: Formação em pesquisa; Psicologia; Teoria do ator-rede.

\section{WAYS OF RESEARCHING EVERYDAY LIFE: THEACTOR-NETWORK THEORY CONTRIBUTION}

ABSTRACT: Using the actor-network theory, this paper describes the practices of becoming educated in research, based on the general subject of the XI ANPPEP Symposium "Ways of searching in everyday life: contributions to the formation of research in Psychology", considering that the author was a participant in the ANPEPP work group "Everyday life and Social Practices". After summarizing a paper of Bruno Latour, a dialogue between a professor and a student in which the main characteristics of the research practice in this approach are outlined, the author exposes in a more accurate manner the epistemological and methodological positioning of the referred theory and its pragmatic philosophical roots, describing briefly some propositions of William James and John Dewey.

KEYWORDS: Education in research; Psychology; Actor-network Theory.

"Maneiras de pesquisar no cotidiano: Contribuições para a formação em pesquisa em Psicologia" foi o tema agregador proposto pela coordenação do GT - Cotidiano e Práticas Sociais para nortear as discussões do grupo no XI Simpósio da Associação Nacional de Pesquisa e PósGraduação em Psicologia (ANPEPP) ocorrido em maio de 2006 em Florianópolis, SC, a partir do objetivo do Simpósio de "delinear perspectivas de ação que contribuam para a formação de docentes e pesquisadores na área." Na apresentação de cada membro do GT a coordenação sugeria um roteiro que expusesse a descrição da situação de pesquisa, da fonte de dados, dos modos de pesquisar, do posicionamento epistemológico-metodológico, da problematização dos aspectos éticos envolvidos e finalmente, as implicações para a formação de pesquisa.

Em minha apresentação procurei mostrar que a ênfase do posicionamento epistemológico-metodológico com a qual estava envolvido recaia no 'como' da pesquisa, que a fonte de dados provinha do cotidiano em suas articulações e proposições e que, enquanto pesquisador alinhado com as proposições da teoria do ator-rede, os modos de pesquisar que eu privilegiava recaiam na des- crição de redes sócio-técnicas. A partir de um texto recente de Latour intitulado "O que fazer do ator-rede? Interlúdio sob a forma de um diálogo" (Latour, 2006) procurei mostrar que nesta abordagem não é o pesquisador que estabelece os aspectos éticos envolvidos na investigação - quem "saberia" são os atores envolvidos, eles seriam os "experts", não o pesquisador. Em termos de implicação para formação de pesquisa, haveria que seguir os atores e formular a eles as boas questões.

No referido diálogo um professor da London School of Economics recebe em sua sala um aluno que deseja utilizar a teoria do ator-rede em sua tese de Doutorado - um estudo de caso sobre organizações. Ele está um tanto perdido e vai procurar o professor, que não é seu orientador, para um esclarecimento quanto a como levar seu trabalho de campo. O diálogo se inicia com o aluno dizendo da sua dificuldade em aplicar a teoria do ator-rede em seu estudo de caso em uma organização. $\mathrm{O}$ professor argumenta que a teoria é útil contanto que não seja aplicável a nada. Ela é antes de tudo um argumento negativo. Ela não diz nada de positivo sobre qualquer estado de coisas. Ela propõe não romper os vínculos entre 
elementos que pareceriam incomensuráveis em categorias acadêmicas normais. Ela não pode positivamente dizer o que é o vínculo. Ela é uma teoria sobre como estudar as coisas, melhor, como não estudá-las, como dar aos atores um espaço para eles se expressarem.

O aluno pondera que na companhia que ele está estudando há muita gente compondo inúmeras redes. $\mathrm{O}$ professor aponta que aí está o problema: é uma perda de tempo utilizar a teoria do ator-rede para dizer isto. Com ela você pode descrever algo que não parece com uma rede - um estado individual da mente, uma peça de maquinaria, um personagem de ficção e, de forma conversa, você pode descrever redes de metrô, de esgoto, de telefones que não foram esboçadas na forma da teoria do ator-rede. Ela é um método que nada diz da forma do que está sendo descrito através dela. Tudo depende do que se entende por ator e o que eles fazem. Não é suficiente estar conectado, interconectado ou ser heterogêneo para constituir uma rede. Depende do tipo de ação que flui do ator para a rede. Ao se quebrar a palavra network tem-se net (rede) e work (trabalho, agência). O professor (que eu penso ser o Latour) sugere ao aluno que ao invés de network ele pensasse em worknet. É a agência e o movimento, o fluxo e as mudanças que deveriam ser ressaltadas. A teoria do ator-rede não é um instrumento; ou melhor, instrumentos não são nunca meros instrumentos a serem aplicados: eles sempre modificam os objetivos que se tinha em mente, propiciando efeitos imprevisíveis.

$\mathrm{O}$ aluno pondera que seu orientador insiste que ele encontre um referencial, uma teoria, um argumento, um ponto em geral, um conceito que dê conta dos seus dados. O professor responde que se ele quer mais dados que compre um disco rígido maior e brinca com a palavra frame, perguntando se seu orientador está no ramo da venda de pinturas - poderia haver molduras de diversos tipos, mas não seria esquisito um artista buscar a moldura antes de pintar um quadro? Mas você não precisa sempre de uma teoria, não precisa sempre colocar as coisas num contexto, se angustia o aluno?

Não, você não precisa, responde o professor! Se alguma coisa é simplesmente o exemplo de um estado de coisas, vá estudar este estado de coisas ao invés do exemplo. Um estudo de caso que necessita de um referencial em adição é um estudo de caso mal escolhido de saída. Se eu fosse você abriria mão dos referenciais, contextualizações. Apenas descreva o estado de coisas ao seu alcance. Os próprios atores produzirão seus referenciais, suas teorias, seus contextos. 'Apenas descreva'.

O aluno pergunta se isto não é por demais inocente e pouco sofisticado. O professor pergunta se o aluno pensa que descrever seja fácil. Descrever, estar atento aos estados concretos e encontrar a forma adequada de dar conta de uma determinada situação é uma atividade que exige muito do pesquisador.

A questão que emerge da discussão é se a teoria do ator-rede reporta a uma sociologia que visa a interpretação ou a objetividade. Certamente o professor não apoiaria esta última. Para a surpresa do aluno não só ele a apóia, mas com todos os meios! Ele que imaginava o professor relativista, defensor da multiplicidade de pontos de vista.

O professor afirma sua opção pela objetividade das ciências. O que mais elas poderiam ser? Elas afinal tratam todas de objetos. Simplesmente tais objetos são um tanto mais complicados, dobrados, múltiplos, complexos, emaranhados que um defensor tradicional da objetividade admitiria. O problema com as sociologias 'interpretativas' é que elas efetuam uma divisão em um mundo de objetos inflexíveis, 'relações causais puras', 'conexões estritamente materiais' por um lado e sentidos, intenções humanas, 'interpretações flexíveis', por outro. Ao se afirmar a existência de realidades objetivas afirma-se a existência de realidades subjetivas.

O professor oferece ao aluno um ensaio de descrição: "Diria que este computador nesta escrivaninha, esta tela, este teclado como objetos, esta escola é composta por muitas camadas, exatamente como você sentado aqui, seu corpo, sua linguagem, suas questões". A hermenêutica sempre leva a uma observação do tipo "mas, claro, há também coisas 'naturais', 'objetivas' que não são interpretadas".

Por outro lado, não há porque negar que temos um ponto de vista, mas a grande vantagem de um ponto de vista é que podemos mudá-lo (um astrônomo tem um ponto de vista limitado em Greenwich, mas modifica sua perspectiva através de instrumentos, telescópios, satélites). Ter um ponto de vista não significa estar 'limitado pela subjetividade'. Se uma coisa suporta muitos pontos de vista é justamente porque é altamente complexa, intrincada, bem organizada, 'objetivamente bela'. Não se trata de relativismo, mas de relatividade. No trabalho de campo, em levantamentos, pesquisas de opinião, nós ouvimos, aprendemos, tornamo-nos competentes, mudamos nossos pontos de vista. O bom trabalho de campo produz uma quantidade de novas descrições. Se uma explicação é relevante, um novo agente está sendo acrescentado à descrição, e a rede é maior do que se imaginava. Se uma descrição precisar de uma explicação ela não será uma boa descrição. A teoria do ator-rede abre mão da explicação.

Inicia-se uma discussão sobre a escrita da tese. Escrever textos diz o professor tem tudo a ver com método. O texto, dependendo como ele for escrito, capturará ou não a rede de atores estudada. Ele é o equivalente a um laboratório. É o lugar das tentativas, experimentos, simulações. Dependendo do que acontece ali haverá ou não um ator ou rede sendo traçados. E isto depende intei- 
ramente na maneira precisa na qual isto está sendo escrito e cada simples novo tópico requer uma nova maneira a ser operada pelo texto.

O aluno protesta, seu orientador não quer uma 'mera descrição', ele precisará estabelecer um referencial a sua descrição, encontrar uma tipologia, comparar, explicar, generalizar. Ele precisa terminar sua tese, ele está em pânico.

O professor pondera que ele deveria entrar em pânico se seus atores não estivessem de forma constante, ativa, reflexiva e obsessiva comparando, produzindo tipologias, projetando parâmetros. Porque só ele atuaria de forma inteligente? O que eles fazem para expandir, relatar, comparar, organizar é o que ele deveria descrever. E isto não é uma 'mera descrição'. Suas idéias próprias sobre sua companhia não são de interesse se comparadas à forma como a companhia se organizou para se desenvolver.

Segue uma longa discussão sobre o estruturalismo e os mecanismos subjacentes. $\mathrm{O}$ aluno pergunta se não seria a mesma proposta. De forma alguma responde o professor. O estruturalismo não transforma, não traduz, os atores não agem. A teoria do ator-rede não aceita trabalhar com estruturas invisíveis, subjacentes. Se elas assumirem formas explícitas aí será possível acompanhá-las.

$\mathrm{O}$ tipo de ciência proposto pela teoria do ator-rede parece romper com todas regras do treinamento em Ciências Sociais conclui o aluno um tanto desalentado.

Prefiro rompê-las e seguir meus atores, responde o professor.

Nesta versão em forma de artigo da minha participação no GT, penso ser necessário precisar melhor o posicionamento epistemológico-metodológico da sociologia do ator-rede. Em Latour (2004), o pensador francês contrasta uma vertente sociológica que reporta à obra de Émile Durkheim com outra que reporta àquela de Gabriel Tarde. O movimento da primeira vertente seria buscar a ordem e a regularidade numa instância geral. Seria preciso fugir da irregularidade do detalhe. $O$ movimento da segunda vertente caminharia no sentido inverso: se nos elevássemos demais perderíamos a possibilidade de investigar como se combinam os componentes de pequenos grupos. Assim, na lingüística, na sociologia, os seguidores de Durkheim dirão que atrás das frases particulares, atrás das multiplicidades, haveria uma lógica imanente, haveria gramáticas, estruturas, categorias e representações que se buscaria detectar, princípios de coordenação no pensamento dos atores. Estes agiriam através das leis que regeriam esta ação. Para os seguidores de Tarde tratar-se-ia de descrever concretamente, continuamente, redes, vínculos, conexões, o pequeno explicando o grande. Assim, por exemplo, o interesse de um lingüista não recairia tanto na linguagem, mas nas falas, o interesse de um econo- mista não recairia tanto no capital, mas nas transações econômicas. Humanos e não humanos não agiriam simplesmente, posto que estariam em redes de relações que não se saberia bem quando começam, quando acabam, redes que não teriam forma estável e nunca se fechariam definitivamente. Ao contrário da outra linha sociológica, para a qual se almejaria a certeza e a segurança de avaliações não hesitantes, a outra proposta incentivaria a heterogeneidade e a multiplicidade, associadas à descrição fina das hesitações causadas pelos laços contínuos entre os objetos. No primeiro modelo o mundo seria traçado a partir de um plano ideal, transcendente, associado a regimes de justificação, fundados no método crítico. No modelo alternativo o plano seria de imanência fundado numa lógica das conexões.

Na primeira proposta sociológica quem estabelece categorias seriam os homens. Na segunda proposta a ênfase recairia nas descrições dos modos de construção e dos modos de existência coletivos. Nesta última abordagem, as categorias surgiriam num processo no qual estão envolvidos homens e seus objetos, humanos e não humanos no jargão da sociologia de Latour. Os objetos não seriam dominados pelos homens, eles estabeleceriam com eles relações complexas, eles os "superariam", participando das categorizações. As relações entre humanos e não humanos estariam tão enredadas que não seria possível separá-las. Tratar-se-ia de compreender os vínculos que estabeleceriam entre eles. Na teoria do ator-rede o conceito do que seria social seria pensado enquanto produzido em rede, através de regimes de existência política que dariam margem a uma sociologia das ciências e das técnicas.

É no contexto teórico da segunda vertente que eu me posiciono. Fica então mais clara a escolha do diálogo acima referido para dar conta das "maneiras de pesquisar no cotidiano" e nas "contribuições para a formação em pesquisa em Psicologia". No decorrer deste diálogo quase socrático entre um aluno perplexo e um professor que não circunscreve a metodologia tradicional de pesquisa em ciências sociais, são expostos com humor, mas também com rigor, as maneiras de pesquisar no cotidiano a partir da proposta da teoria do ator-rede. Tendo em vista que, como docente do Programa de Pós-Graduação em Psicologia Social da Universidade do Estado do Rio de Janeiro, venho orientando meus mestrandos e doutorandos a partir desta vertente sociológica, posso confirmar na prática a acuidade da descrição efetuada por Latour destas maneiras de pesquisar, inclusive as perplexidades e desalentos às vezes vividos pelos alunos.

Julgo ainda pertinente ressaltar a base conceitual pragmática da sociologia do ator-rede. Dois importantes livros permitem expor aqui alguns princípios desta corrente filosófica: o primeiro de David Lapoujade (1997) e o segundo de John Dewey (1955). O texto de Lapoujade 
trata do empirismo e do pragmatismo decorrente das propostas do filósofo e psicólogo do séc. XIX, William James. Para James, tal como para o professor, não existem coisas, mas coisas se fazendo: é preciso seguir as funções. A forma como James e Lapoujade tratam do conceito de verdade é muito próxima à forma pela qual Latour lida com a base teórica ou a estrutura no debate com o aluno. "O que permite ao racionalismo dizer que uma idéia é verdadeira em si própria?" pergunta Lapoujade. "É que ele examina a verdade a partir de idéias já constituídas, crenças já verificadas, isto é, freqüentemente, hábitos. Com efeito, é apenas quando a idéia volta, num hábito, que se pode dizer que ela já era verdadeira nela mesma. $\mathrm{O}$ racionalismo vem em seguida. Como sempre, ele não tem outra opção que efetuar um julgamento retroativo e dizer que a idéia era já intrinsecamente verdadeira, que nós descobrimos sua preexistência a partir de suas consequiências. O mundo estava lá antes que descobríssemos sua existência. O que é verdadeiro é verdadeiro desde sempre" (p. 57). Ora, não é nada disto, sustenta Lapoujade. "Em termos pragmáticos, a questão se formula assim: qual o processo pelo qual a verdade se constrói?” (p. 49). Citando o próprio James, ele responde: “A verdade de uma idéia não é uma propriedade estática que lhe seja inerente. A verdade chega a uma idéia. Ela se torna verdadeira a partir dos acontecimentos." Ela é "um nome coletivo para um processo de verificação.” O pragmatismo:

$$
\begin{aligned}
& \text { propõe menos uma nova definição de verdade do } \\
& \text { que um método de experimentação, de construção, } \\
& \text { para novas verdades. Experimentar é considerar a } \\
& \text { teoria como prática criadora. É porque não se trata } \\
& \text { mais de saber o que é verdadeiro, mas como se faz o } \\
& \text { verdadeiro. E esta questão é ela mesma inseparável } \\
& \text { de outra: o que faz o verdadeiro? ... Uma idéia verda- } \\
& \text { deira não é apenas o que acreditamos, fazemos ou } \\
& \text { pensamos; é o que faz crer, faz agir ou faz pensar... } \\
& \text { Não se julga mais uma idéia, uma doutrina, um enun- } \\
& \text { ciado em função de sua verdade; é, ao contrário a } \\
& \text { verdade de uma idéia, de uma doutrina, de um enun- } \\
& \text { ciado que é avaliada em função das suas conseqü- } \\
& \text { ências para o pensamento, a ação, a crença. } \\
& \text { (Lapoujade, 1997, p. 59-60). }
\end{aligned}
$$

Ora, a teoria do ator-rede propõe precisamente buscar descrever o que faz fazer (Latour, 1998).

O texto de Dewey (1955) foi originalmente publicado após a $1^{\text {a }}$ Guerra Mundial, em 1920. Em sua reedição, em 1948, o autor redige uma nova introdução intitulada " $A$ reconstrução vista vinte cinco anos depois”. Alguns dos principais argumentos da teoria do ator-rede já se encontravam ali esboçados. $\mathrm{O}$ autor inicia o texto sustentando que mais do que uma reconstrução na filosofia seria necessária uma reconstrução $d a$ filosofia. Os eventos que aconteceram no período considerado tornaram claro para ele que os problemas e temáticas da filosofia nascem das tensões da vida cotidiana na qual emergem a filosofia e seus problemas específicos. Após a $1^{\mathrm{a}}$ Guerra Mundial, insegurança e incerteza tomaram o lugar do antigo otimismo no progresso e nas garantias de harmonia e paz. A falta de confiança na filosofia manifestada no refinamento de técnicas que buscam a pureza formal expressa o desejo de encontrar algo fixo e certo que proporcione um refúgio seguro frente às incertezas. $\mathrm{O}$ aumento de erudição, porém, indica a ausência da cena presente.

Por outro lado, a reconstrução a ser efetuada deve trazer para a investigação de temas humanos e morais o mesmo método através do qual foi possível atingir uma compreensão da natureza física. Isto implica em repensar a teoria do conhecimento: a nova teoria deverá considerar como o conhecer, a pesquisa competente, se efetua, ao invés de supor que ele deva se conformar a visões formadas independentemente da pesquisa. Abandonar a assunção de fixidez, a demanda de princípios não temporais, parâmetros, normas, fins como a única proteção contra o caos moral, será reconhecer a afirmação revolucionária de que "universais" são processos de mudança. Isto leva a repensar a concepção de ciência. Ela é uma busca, que "afeta de forma perturbadora todo aspecto da vida contemporânea" (Dewey, 1955, p. 16). A reconstrução da filosofia visaria precisamente encontrar hipóteses que dessem conta desta transformação. A inegável entrada da ciência em nossa vida comum não foi acompanhada de esforços sistemáticos para submeter os códigos morais subjacentes aos velhos hábitos instituídos na pesquisa e crítica científicas. A filosofia deveria encarregar-se de fazer para o desenvolvimento da pesquisa em assuntos humanos e logo em assuntos morais o que os filósofos dos últimos séculos fizeram para a promoção da pesquisa científica das condições físicas e fisiológicas e de aspectos da vida humana. Em outros termos, a ciência não opera num vazio, ela trabalha num contexto institucional ainda não modificado desenvolvido numa época pré-científica onde foram formados os princípios morais que eram naquela ocasião presumivelmente apropriados. Seria preciso investigar séria e sistematicamente estas condições institucionais e suas conseqüências. A reconstrução pretendida por Dewey seria, portanto, o desenvolvimento, a formação, a produção de instrumentos intelectuais que irão progressivamente dirigir a pesquisa aos fatos da cena e da situação presentes. Assim, a reconstrução da filosofia vem acompanhada da reconstrução da ciência. Há que se reconhecer que a ciência envolvida em nosso dia a dia ainda é parcial e incompleta: há uma incompatibilidade entre operações que manifestam e perpetuam valores de épocas précientíficas e operações provenientes das pesquisas das ciências físicas e naturais.

Será a partir da prática que esta incompatibilidade poderá ser desfeita. A ciência como conduzida, a ciência na prática, conclui Dewey, repudiou completamente as separações entre ciência superior e inferior ${ }^{1}$. A investiga- 
ção científica criou atividades, materiais, instrumentos, exemplos de procedimentos antes vistos como meramente práticos num sentido utilitarista e os incorporou ao seu escopo. A teoria na conduta da pesquisa científica deixou de ser o fator último. Teorias passaram a ser hipóteses. A ordem de instâncias fixas passou irrevogavelmente para uma "ordem de conexões em processo" (1955, p. 28). Em sua reconstrução a filosofia deverá reunir (assemble) e apresentar as razões de porque a separação antigamente colocada entre teoria e prática não existe mais.

Nada mais latouriano.

\section{Notas}

${ }^{1}$ Meio século antes dos teóricos da Teoria do Ator-Rede, Dewey já questionava as dicotomias modernas das ciências superiores, do espírito versus ciências mais baixas ou inferiores, físicas ou materiais.

\section{Referências}

Dewey, J. (1955). Reconstruction as seen twenty-five years later. In J. Dewey. Reconstruction in Philosophy (6. ed.). New York: Menton Books.

Lapoujade, D. (1997). William James, Empirisme et Pragmatisme. Paris: Presses Universitaires de France.

Latour, B. (1998). Faktura: de la notion de réseaux à celle d'attachements. In A. Micoud \& M. Peroni (Eds.), Ce qui nous relie (pp. 189-208). La Tour d'Aigues, France: Editions de l'Aube. Retirado em 03 mar. 2005, de http://www.ensmp.fr/ latour/articles/article/076.html

Latour, B. (2004). Dialogue sur deux systèmes de sociologie. In M. Breviglieri, C. Lafaye \& D. Trom (Eds.), Sens de la justice, sens critique. Paris: Economica. Retirado em 10 ago. 2005, de http:/ /www.ensmp.fr/ latour/articles/article/95-GSPM.html

Latour, B. (2006). Que faire de l'acteur-réseau? Interlude sous forme de dialogue. In B. Latour. Changer de société - Refaire de la sociologie. Paris: Éditions de la Découverte.

Ronald João Jacques Arendt é doutor e professor titular em Psicologia Social do Programa de PósGraduação em Psicologia Social da Universidade do Estado do Rio de Janeiro. É membro do GT "Cotidiano e Práticas Sociais" da ANPPEP. Este texto é o paper da apresentação XI Seminário da ANPPEP ocorrido em maio de 2006 em Florianópolis, Santa Catarina. Endereço para correspondência: Rua Afonso Pena,

141/601, Tijuca, Rio de Janeiro, RJ, 20270-241

\section{ronald.arendt@oi.com.br}

Maneiras de Pesquisar no Cotidiano: Contribuição da

Teoria do Ator-Rede

Ronald João Jacques Arendt

Recebido: 21/06/2006

$1^{\text {a }}$ revisão: 05/09/2007

Aceite final: 16/10/2007 